\title{
Multifunctional photoprotection: corrective makeup for cutaneous dyschromias
}

\author{
Felipe da Silva Gonçalves ${ }^{1}$, Iris Ramos Torres Giovanini ${ }^{1}$, Cristal Cerqueira ${ }^{2}$, \\ Eduardo Ricci Junior ${ }^{1}$, Zaida Maria Faria de Freitas ${ }^{1}$, Elisabete Pereira dos Santos ${ }^{{ }^{*}}$ \\ ${ }^{1}$ Department of Medicines, Pharmacy Faculty, Federal University of Rio de Janeiro, Rio de Janeiro, Brazil, \\ ${ }^{2}$ Institute of Macromolecules Professor Eloisa Mano, Federal University of Rio de Janeiro, Rio de Janeiro, Brazil
}

\begin{abstract}
The aim of this study was to develop and evaluate a corrective and photoprotective makeup for patients with dyschromias. An emulsion was prepared and pigment mixtures were incorporated in the formulation, producing five shades of corrective makeup: BEIGE (I, II, III), BRONZE and TAN. The sun protection factor (SPF) and UVA/UVB ratio of the corrective makeup were determined using spectrophotometry with a Labsphere ${ }^{\circledR}$ analyser. The spreadability, occlusivity, stability, and photostability of the photoprotective formulations were also evaluated. For all formulations there was no statistical difference among them $(p>0.05)$ in terms of spreadability, occlusivity and SPF. They were considered to be photostable under solar radiation, with variations in SPF value and UVA/UVB ratio lower than $20 \%$. The corrective makeup presented average-to-high UVB photoprotection and broad spectrum photoprotection. After 90 days, $\mathrm{pH}$, density and SPF values showed no significant differences among formulations $(p>0.05)$. All corrective makeup presented separation of the pigments, however, they returned to a homogeneous aspect and to the original color shade after shaking. The corrective makeup presented a fine texture, little brightness, and a homogeneous, dry-to-the-touch aspect. This work may benefit patients with dyschromias, improving their quality of life, besides promoting photoprotection and covering the skin blemishes.
\end{abstract}

Keywords: Corrective makeup. Dyschromias. Sunscreens. Emulsions cosmetics.

\section{INTRODUCTION}

The skin is an organ with various functions. These include the protection of the internal structures of the body, synthesis of vitamin $\mathrm{D}$, production of keratin, protection against UV radiation, and ability to receive information through sensory nerves. The relationship between the nervous system and skin makes it very sensitive to emotions, and a person's feelings can be expressed on the skin without their intention. Moreover, skin diseases can have multifaceted causes, including an interaction of social, biological, and psychological factors (Longo et al., 2013; Lai-Cheong, MacGrath, 2013; Stiefel, Schwack, 2015).

Some skin diseases are characterized by alteration of pigmentation and formation of macules of different sizes. These blemishes can be bilateral, symmetrical or

*Correspondence: E. P. Santos. Departamento de Medicamentos, Faculdade de Farmácia, Universidade Federal do Rio de Janeiro. Avenida Carlos Chagas Filho, 373, 21941-902 - Rio de Janeiro, Brazil. Phone number: +55 2139386625. E-mail: bete@pharma.ufrj.br asymmetrical, and can eventually affect the entire surface of the skin (Ayanlowo et al., 2009). Vitiligo, rosacea, acne and lupus are examples of these pigmentation disorders that may be disfiguring, and can have a significant negative impact on self-esteem. The diseases characterized by cutaneous dyschromias can lead to a general poor sense of well-being, which can manifest in physical, emotional, and social aspects (Krüger, Schallreuter, 2012; Dwivedi et al., 2015).

Many different theories have been proposed to explain the origins of different dyschromias since there are no agreement or uniformity of views regarding the etiology of them. However, many researchers suggest emotional factors related to stress as the main cause for the emergence and development of these diseases (Hossain et al., 2016). In the field of dermatology, some studies indicate that the emergence of several skin diseases can be directly related to psychosocial factors (Thompson et al., 2010).

Corrective makeup represents a therapeutic modality that may help to reduce the psychological stress of 
patients with deforming congenital or acquired lesions that are not responsive to clinical or surgical treatments. Furthermore, corrective makeup are generally mixtures of different components designed to cover skin deformities and imperfections in individuals of any age, sex, and race. These products are intended to improve appearance and self-esteem as well as quality of life, thus fostering social inclusion (Levy, Emer, 2012; Seité et al., 2012; Tanioka et al., 2010).

In recent years, corrective makeup has been improved thanks to the addition of new components that provide additional benefits such as photoprotection. The use of broad-spectrum sunscreens is essential for the prevention of skin cancers. Patients with hypomelanosis are usually susceptible to developing cutaneous malign neoplasms due to a lack of melanin in the affected skin. Thus, the use of photoprotectors is of paramount importance in patients with these cutaneous pathologies (Sarveswari, 2010; Kaliyadan, Kumar, 2012).

The present study aimed to develop and test a specific photoprotective makeup. We used physicochemical assessments to ensure that it is useful for patients with dyschromias. The makeup features different shades to cover up cutaneous spots on different skin tones.

\section{MATERIAL AND METHODS}

\section{Material}

Red (ferric oxide), yellow (hydrated ferric oxide), and black (ferric-ferrous oxide) pigments were obtained from Kingfisher Colours Ltd. (England), while white pigment (99\% titanium dioxide by weight) was obtained from Sensient Colors Latin America (Mexico). Benzophenone 3, octocrylene, and octylmethoxycinnamate photoprotectors were acquired from Guangzhou Shiny (China), Chemspec Chemicals Pvt. Ltd. (India), and Wsb (England), respectively. Propylene glycol and glycerin were purchased from Dow Chemicals Company (USA) and KLK OLEO (Malaysia), respectively. Polysorbate 80 (Tween $80^{\circledR}$ ) was obtained from Oxiteno (Brazil), while aminomethyl propanol $95 \%$ was obtained from the Angus Chemical Company (Germany). Aluminum octenylsuccinate polymer starch (Dry Flo Pure ${ }^{\circledR}$ ), copolymer of sulfonic acryloyldimethyltaurate acid (Aristoflex $\mathrm{AVC}^{\circledR}$ ), and copolymer of methylmethacrylate crosspolymer (Makibeads $80^{\circledR}$ ) were purchased from Akzonobel (USA), Clariant-Suzano (Spain), and Daito Kasei Europe (France). The preservatives used to prepare the corrective makeup were methylparaben that was obtained from Sharon Chemical Factories Ltd. (Israel), propylparaben from Zhejiang ShengXiao Chemicals (China), and imidazolidinil urea from Changzhou Comwin (China). The emollients used were isocetyl stereate, obtained from Solvay Rhodia (Brazil), and neopentylglycol diheptanoate and isododecane (Lexfeel D5 ${ }^{\circledR}$ ), obtained from Inolex Chemical Company (USA). The emulsifying surfactants used were cetostearyl alcohol ethoxylate from Chemspecs/Basf Company (Brazil), stearic acid from Materia Oleochemicals (Argentina), and glyceryl monostearate from Dhaymers Ind. \& Com. de Prod. Químicos Ltd. (Brazil). The liquid petroleum jelly used in the determination of sun protection factors (SPF) was obtained from Calumet Specialty Products Partners (USA).

\section{Development of pigment mixtures}

Mixtures of pigments were homogenized and sieved in a Granutest ${ }^{\circledR}$ granulometric sieve with a $420 \mu \mathrm{m}$ mesh. The contents were then transferred back to the glass mortar and mixed once more using the pestle (Mollet, Grubenmann, 2008). In Table I, the pigments used in the development of mixtures are presented, as well as their respective color index codes (Brandão, 2009a).

TABLE I - Pigments used to the development of mixtures

\begin{tabular}{lc}
\hline PIGMENT & SUBSTANCE \\
\hline WHITE (CI 77891) & Titanium Dioxide \\
RED (CI 77491) & Hydrated Ferric Oxide \\
YELLOW (CI 77492) & Ferric Oxide \\
BLACK (CI 77499) & Ferrous Ferric Oxide \\
\hline
\end{tabular}

$\overline{\mathrm{CI}}$ - Colour Index codified by the Brazilian Association of Cosmetology

The pigments used were mixed in various concentrations to allow the production of different skin tones.

\section{Preparing photoprotective makeup}

The oil-phase components were warmed to $80{ }^{\circ} \mathrm{C}$, then the aqueous phase was added and homogenized under light heating. This emulsive base (NPB1) described in Table II was stored for $24 \mathrm{~h}$.

Thereafter each pre-prepared pigment mixtures, the aluminium starch octenylsuccinate polymer and copolymer of methyl methacrylate crosspolymer were added in a glass mortar, and levigated in propylene glycol with a pestle. A small amount of NPB1 base was 
added to the mortar, and the contents were homogenized with the pestle. The concentrations and purposes of each component used in the process of incorporating the pigment mixtures are presented in Table III.

Another emulsive base (NPB2) was prepared without the addition of the pigments (only NPB1-based polymers were incorporated).

\section{Determination of the in vitro SPF of non-pigmented NPB1 base by UV spectrophotometric absorbance}

of NPB1 in ethanol were prepared. These solutions were then subjected to analysis in a JASGO V-630 UV/VIS spectrophotometer to determine absorbance in the wavelength range 290-320 $\mathrm{nm}$. Absorbance was read at each $5 \mathrm{~nm}$ interval as shown in Table IV (Mansur, et al., 1986; Santos et al., 1999; Freitas et al., 2001; Mansur et al., 2016).

A mathematical equation (Eq. 1) was used to determining the SPF of the NPB1 base. This equation uses the erythematous effect and the intensity of radiation (EE x I), as described in Table IV (Mansur, et al., 1986).

Three solutions with final concentrations of $0.2 \mu \mathrm{g} / \mathrm{mL} \quad$ SPF spectrophotometric $=\mathrm{CF} \cdot \sum_{290}^{320} \cdot \mathrm{EE}(\lambda) \cdot \mathrm{I}(\lambda) \cdot \operatorname{abs}(\lambda)(1)$

TABLE II - Formulation of non-pigmented and photoprotective emulsive base (NPB1)

\begin{tabular}{ccc}
\hline Substance & Concentration & Function \\
\hline AQUEOUS PHASE & & Humectant \\
Glycerin & $5 \%$ & Preservative \\
Methylparaben & $0,1 \%$ & Neutralyzing Agent \\
Aminomethylpropanol 95\% & $0,2 \%$ & Preservative \\
Imidazolidinyl Urea & $0,2 \%$ & Thickner \\
Ammonium Acryloyldimethyl-Taurate/VP Copolymer & $0,2 \%$ & Vehicle \\
Distilled Water & qsp. ${ }^{(1)} .100 \mathrm{~g}$ & \\
\hline OIL PHASE & & Emollient \\
\hline Neopentyl Glycol Diheptanoate and Isododecane & $5 \%$ & Emulsifier \\
Cetostearyl Alcohol Ethoxylate & $5 \%$ & Emulsifier and Thickner \\
Stearic Acid & $4 \%$ & Emollient \\
Isoctyl Stearate & $7 \%$ & Emollient and Emulsifier \\
Gliceryl Monostearate & $2 \%$ & Preservative \\
Propylparaben & $0,1 \%$ & Emulsifier \\
Polysorbate 80 & $0,6 \%$ & UVA and UVB Sun Filter \\
\hline PHASE C ${ }^{(2)}$ & & UVB Sun Filter \\
\hline Benzophenone 3 & $8 \%$ & UVA and UVB Sun Filter \\
\hline Octylmethoxycinnamate & $10 \%$ &
\end{tabular}

(1) An abbreviation in Latin for "quantum satis para" (2) Phase consisting of UVA e UVB sun filters

TABLE III - Incorporation of the pigment mixtures into the formulation of the photoprotective emulsive base

\begin{tabular}{ccc}
\hline Substance & Concentration & Function \\
\hline Mixture of pigments & $10 \%$ & Pigmentation \\
Propyleneglycol & $10 \%$ & Humectant \\
copolymer of methyl methacrylate crosspolymer & $3 \%$ & Reduce the brightness \\
Aluminum starch octenylsuccinate & $3 \%$ & Reduce the oleosity \\
Photoprotective Emulsive Base (NPB1) & $\mathrm{qsp}^{(1)} .100 \mathrm{~g}$ & Vehicle \\
\hline
\end{tabular}

(1) An abbreviation in Latin for "quantum satis para" which means "sufficient quantity for" in English. 
TABLE IV - Relationship between radiation intensity and erythematogenic effect at each wavelength

\begin{tabular}{cc}
\hline $\boldsymbol{\lambda}(\mathbf{n m})$ & $\mathbf{E E}(\boldsymbol{\lambda}) \mathbf{x} \mathbf{I}(\boldsymbol{\lambda})$ \\
\hline 290 & 0.0150 \\
295 & 0.0817 \\
300 & 0.2874 \\
305 & 0.3278 \\
310 & 0.1864 \\
315 & 0.0839 \\
320 & 0.0180 \\
\hline
\end{tabular}

where $\mathrm{CF}$ is the correction factor $(\mathrm{CF}=10) ; \mathrm{EE}(\lambda)$ is the erythematous effect of radiation at a given wavelength $(\lambda) ; \mathrm{I}(\lambda)$ is the intensity of sunlight at a given wavelength $(\lambda)$; and $\operatorname{abs}(\lambda)$ is the spectrophotometric absorbance of the solution at a given wavelength (Mansur et al., 1986).

\section{Determination of SPF, UVA/UVB ratio, and $\lambda c$ of the NPB1 base, NPB2 base, and corrective makeup using Labsphere ${ }^{\circledR}$ spectrophotometric transmittance}

In vitro SPF testing was performed using transmittance spectrophotometry with a Labsphere ${ }^{\circledR}$ integrating sphere and a $25 \mathrm{~cm}^{2}$ quartz plates properly coated with Transpore ${ }^{\circledR} 3 \mathrm{M}$ film. The sunscreen formulations were deposited and evenly overspread on the plates at $1.2 \mathrm{mg} / \mathrm{cm}^{2}$ (equivalent to $30 \mathrm{mg}$ ). After 15 min protected from light, the samples were read and the in vitro SPF values were obtained (Miksa, Lutz, Guy, 2014; Miksa, Lutz, Guy, 2015; Cerqueira-Coutinho et al., 2015). The analysis was carried out in triplicate.

\section{Determination of the photostability of NPB2 base and corrective makeup}

The initial in vitro SPF of the samples were assessed in triplicate by transmittance spectrophotometry with a Labsphere ${ }^{\circledR}$. Each sample was then weighed in an $8.5 \mathrm{~cm}^{2}$ petri dish $(250 \mathrm{mg})$, equivalent to approximately $30 \mathrm{mg} / \mathrm{cm}^{2}$. The samples were distributed evenly across the surface of the plates with a thin spatula. The plates with the samples were then weighed and exposed to natural sunlight between 9:00 and 15:00 hours. The experiment was performed on a sunny summer's day in the urban area of Rio de Janeiro with no clouds. The amount of UV radiation reaching the plates was measured every $30 \mathrm{~min}$ using a portable Light Meter MRU 201 (Instrutherm).
Every 2 hours, the petri dishes containing the samples were subjected to SPF analysis, where $30 \mathrm{mg}$ $\left(1.2 \mathrm{mg} / \mathrm{cm}^{2}\right)$ were transferred from each plate to $25 \mathrm{~cm}^{2}$ quartz plates coated with Transpore ${ }^{\circledR} 3 \mathrm{M}$ film to produce a uniform spread. Then, the samples were examined using transmittance spectrophotometry with a Labsphere ${ }^{\circledR}$ (Hojerová, Medovcíková, Mikula, 2011). Photostability can be determined by comparing the SPF of sunscreen after solar radiation compared with the in vitro SPF value before UV irradiation. Garoli and collaborators (2008) considered sunscreen displaying SPF percentage variation $<20 \%$ as photostable.

According to this parameter, photostability was expressed as the percentage effectiveness after sun exposure (\% FPS eff $)$, assessed according to Eq. 2, considering products with a $\% \mathrm{FPS}_{\text {eff }}$ of at least $80 \%$ as photostable.

$$
\% \mathrm{FPS}_{\text {eff }}=\frac{\text { FPS in vitro after }}{\text { FPS in vitro before }} \times 100
$$

The same criteria used for determining photostability based on SPF values was used for the values of UVA/ UVB ratio before and after solar irradiation. Therefore, products with percentage changes in UVA/UVB $<20 \%$ were considered photostable (Garoli et al., 2008).

\section{Stability study and physicochemical tests}

The non-pigmented NPB2 sample and the corrective makeup were subjected to an accelerated stability test, in which they were kept for $90 \mathrm{~d}$ at $37.0 \pm 2.0^{\circ} \mathrm{C}$ in a greenhouse, $5.0 \pm 2.0{ }^{\circ} \mathrm{C}$ in a fridge, and $23.0 \pm 2.0{ }^{\circ} \mathrm{C}$ at room temperature. The samples were evaluated in triplicate at time zero and, subsequently, at 7, 15, 30, 60, and 90 days (Anvisa, 2004).

All preparations underwent visual inspection before any other type of analysis, and were studied with respect to their organoleptic characteristics such as aspect, change in color, and odor. Physicochemical characteristics, such as phase separation (centrifugation test), density, and $\mathrm{pH}$ were also assessed (Anvisa, 2004; Smaoui et al., 2013). The SPF variation of the formulations was also observed during the stability tests (Miksa, Lutz, Guy, 2015; Cerqueira-Coutinho et al., 2015; Mansur et al., 2016).

\section{Centrifugation}

Centrifugation was performed by weighing $5 \mathrm{~g}$ of each sample in a test tube with a capacity of $10 \mathrm{~g}$. All samples were centrifuged using a Beckman Coulter 
Avanti ${ }^{\mathrm{TM}} \mathrm{J} 25$ centrifuge at an internal room temperature of $25.0^{\circ} \mathrm{C}$ with a rotation speed of $3000 \mathrm{rpm}$ for $30 \mathrm{~min}$. Three readings were taken for each sample (Anvisa, 2004; Smaoui et al., 2013).

\section{Determination of $\mathrm{pH}$}

Potentiometric determination of $\mathrm{pH}$ was performed in a Meter 922 digital potentiometer by direct immersion of the electrode in the sample at $25^{\circ} \mathrm{C}$. The analysis was performed in triplicate (Clares et al., 2011; Smaoui et al., 2013).

\section{Density}

A $25 \mathrm{~mL}$ Hubbard-Carmick glass pycnometer for specific gravity was used to determine density. The Eq. 3 was used to assess density (Clares et al., 2011; Smaoui et al., 2013).

$$
\mathrm{d}=\left(\mathrm{M}_{2}-\mathrm{M}_{1}\right) /\left(\mathrm{M}_{1}-\mathrm{M}_{0}\right)
$$

where $\mathrm{d}$ is density; $\mathrm{M}_{0}$ is the mass of the empty pycnometer in $g ; M_{1}$ is the mass of the pycnometer with purified water in $\mathrm{g}$; and $\mathrm{M}_{2}$ is the mass of the pycnometer with the sample in $\mathrm{g}$.

\section{SPF variation}

SPF variations were evaluated in triplicate by transmittance spectrophotometry with a Labsphere ${ }^{\circledR}$ (Miksa, Lutz, Guy, 2015; Cerqueira-Coutinho et al., 2015; Mansur et al., 2016).

\section{Determination of the spreadability of NPB2 base and corrective makeup}

Initially, the sides of a microscope slide were drawn on a sheet of graph paper. Then, the diagonals of the rectangle formed were drawn to indicate the central point. A $25 \mathrm{mg}$ sample of non-pigmented NPB2 base and each corrective makeup variant were placed on the center of a microscope slide, which was positioned over the drawing made on the graph paper. Another glass slide of a given weight $(5.1 \mathrm{~g})$ was then gently positioned on the first containing the sample, and after $1 \mathrm{~min}$, it was scored the diameter of the circle formed by spreading the formulation. The same procedure was performed twice more at $1 \mathrm{~min}$ intervals using $2 \mathrm{~g}$ weights. Four determinations were performed for each sample. In the fourth, the last weight added was $5 \mathrm{~g}$ (Fernándes-Montes, 2005).

The experiment was performed at room temperature and in triplicate for each sample. The areas of the corresponding surfaces were assessed based on the obtained diameters, as well as their averages (Fernándes-Montes, 2005). Spreadability was determined from Eq. 4.

$$
\mathrm{Ei}=\mathrm{d}^{2} \times \pi / 4
$$

where $\mathrm{Ei}$ is the sample spreadability for a given weight in $\left(\mathrm{mm}^{2}\right)$; $\mathrm{d}$ is the diameter in $(\mathrm{mm})$; and $\pi$ is equal to 3.14 .

\section{Determination of the occlusive effect of NPB1, NPB2 and corrective makeup}

To determine the occlusive effect of the formulations, $40 \mathrm{~mL}$ glasses with a diameter of $4.6 \mathrm{~cm}$ were filled with $30 \mathrm{~g}$ of distilled water and covered with filter paper (filter paper: $90 \mathrm{~mm}$; Whatman number: 6; size of cut: $3 \mu \mathrm{m}$ ). The samples were scattered evenly on the filters (13.3 $\mathrm{mg} / \mathrm{cm}^{2}$ ) with a finger cot and stored in a greenhouse at $40^{\circ} \mathrm{C}$ for 48 hours. The entire experiment was carried out in triplicate. The weight of water that remained in the glass jars was verified using a semi-analytical scales after 6,24 , and $48 \mathrm{~h}$. The glass jars covered with filter paper without the application of samples were used as references (Wissing, Müller, 2002; Teeranachaideekul et al., 2008). The factor of occlusion (F) for each product was assessed according to Eq. 5.

$$
\mathrm{F}=[(\mathrm{A}-\mathrm{B}) / \mathrm{A}] \times 100
$$

where A represents loss of water without the sample present (reference) and B represents loss of water with the sample present.

\section{Statistical analysis}

All experiments were performed in triplicate and the results were expressed as averages or means \pm standard deviations. Origin ${ }^{\circledR}$ version 8.0 for Windows software was used for the results that were submitted to the statistical analysis. Analysis of variance was performed with a statistical significance level of $95 \%(\alpha=0.05)$.

\section{RESULTS AND DISCUSSION}

\section{Development of pigment mixtures}

The white, yellow, red, and black pigments used in the development of mixtures were mixed with each other in different proportions to produce five different shades: BEIGE I, BEIGE II, BEIGE III, BRONZE and TAN. The pigment proportions used and the resulting shades are presented in Table V. 
TABLE V - Proportions of mixed pigments and the resulting different shades

\begin{tabular}{cccccc}
\hline SHADES & BEIGE I & BEIGE II & BEIGE III & BRONZE & TAN \\
\hline PIGMENTS & & & & & \\
WHITE & $70 \%$ & $61 \%$ & $73 \%$ & $80 \%$ & $47 \%$ \\
YELLOW & $21 \%$ & $26 \%$ & $10 \%$ & $7 \%$ & $36 \%$ \\
RED & $7 \%$ & $9 \%$ & $15 \%$ & $8 \%$ & $13 \%$ \\
BLACK & $2 \%$ & $4 \%$ & $2 \%$ & $5 \%$ & $4 \%$ \\
\hline
\end{tabular}

\section{Development of corrective and photoprotective makeup}

The NPB1 base developed was an O/W emulsion, and had a homogeneous aspect, fine texture, slightly yellowish color, and a particular odor. Mixtures of pigments were incorporated to the NPB1 base, producing shades to be used on skin phototypes IV to VI according to the Fitzpatrick scale (Fitzpatrick, 1988). Each pigmented emulsion received the same denominations of the prepared pigment mixtures: BEIGE I, BEIGE II, BEIGE III, BRONZE, and TAN.

Despite the homogeneous aspect, fine texture, and good spreadability, after incorporating pigments into the emulsive base, it was noticed that the formulation was oily and shiny, which would not be appropriate to be used on achromic cutaneous spots, since the purpose of makeup in this case is to promote an opaque and natural appearance. Any makeup for this purpose should therefore cover imperfections while providing the skin with a silky, velvety and dry touch (Antoniou, Stefanaki, 2006). Consequently, two substances were added to the formulation. The first was aluminum starch octenylsuccinate, a polymer that acts to reduce skin oiliness, improve the tactic properties of the sunscreen emulsion, and increase SPF (Brandão, 2009a). The second was methylmethacrylate crosspolymer, which reduces skin brightness. It can absorb oiliness, promote a dry touch, and produce a matte, sensorial, and velvety effect on the skin (Brandão, 2009b).

Five rectangles of $6 \mathrm{~cm}^{2}$ were drawn on a white board to highlight the effect of these two substances. Corrective makeup containing either polymers ( $1 \%$ concentration) were then applied in rectangles and visual observation was performed. A second application was performed with the same makeup, together with the two substances at $2 \%$, and finally a third application with both substances at $3 \%$. In each area, $12 \mathrm{mg}$ of photoprotective makeup were applied. Increasing the concentration of the polymers at the formulations produced a drier-to-the-touch bases, with less oiliness and brightness. Thus, the concentration of $3 \%$ was considered the most suitable for both polymers.

\section{Determination of the in vitro SPF of non-pigmented NPB1 base for UV spectrophotometric absorbance}

The average in vitro SPF value of the NPB1 formulation obtained after testing in triplicate was $27.93 \pm 0.19$. The Mansur method (Mansur, et al., 1986) was employed to determine the in vitro SPF of the nonpigmented base without polymers (NPB1) because it is effective and fast. In addition, this method also shows a good correlation with results that can be found at the in vivo assays, and it is widely described at literature (Mansur et al., 2016).

The SPF of the non-pigmented base containing polymers to reduce the brightness and the oiliness (NPB2) and the corrective makeup were not evaluated by the Mansur method (Mansur, et al., 1986), since the formulations had insoluble substances in solvents normally used in this method.

\section{Determination of SPF, UVA/UVB ratio, and $\lambda c$ of the NPB1 base, NPB2 base, and corrective makeup by spectrophotometric transmittance}

The average in vitro SPF values, in vitro UVA/ UVB ratios and $\lambda c$ of the samples obtained in triplicate by transmittance spectrophotometry are shown in Table VI.

The results were expressed as means \pm standard deviations and indicated that the SPF values were not statistically different $(\mathrm{p}>0.05)$ between the nonpigmented bases and corrective makeup. According to Anvisa ${ }^{1}$ (2012), sunscreens could be classified according to their photoprotection determined by measured SPF values. Sunscreen labels must state the category of protection against UVA and UVB radiation. Consequently, considering the standard deviations found

${ }^{1}$ ANVISA (Agência Nacional de Vigilância Sanitária) is a Brazilian department that is similar to the USA's Food and Drug Administration department. 
in the present study, all samples remained in the averagehigh photoprotection category.

The standard deviations of SPF values were probably high because during the application of formulations on quartz plates, the spreadability of formulations on the substrate was one of the critical aspects. The application of a homogeneous film can promote constant SPF values in different regions of the plate and, consequently, lower the standard deviation of values recorded.

Based on the Boots Star Rating System, the effectiveness of a sunscreen product against UVA radiation can be classified by the determination of the UVA/ UVB ratio. According to the 2004 Revised Guidelines for Measurement Practice of UVA/UVB ratio, the greater the UVA/ UVB, the greater the protection against UVA radiation (Labsphere, 2008). Nonetheless, based on the same guidelines and in accordance with the Boots Star Rating System, none of the formulations could be rated since they presented an initial ratio lower than 0.56 . However, the ratios were constant for all formulations after irradiation, which means that the efficacy against UV radiation was kept.

According to COLIPA (2009), a sunscreen should have a $\lambda \mathrm{c}$ value $>370 \mathrm{~nm}$ to be considered as having broad-spectrum protection against UVA radiation. When the $\lambda \mathrm{c}$ value is between 340 and $370 \mathrm{~nm}$, the level of protection against UVA radiation can be classified as intermediate. Thus, a higher $\lambda \mathrm{c}$ value indicates greater UVA photoprotection (Polefka, Meyer, 2012; Cerqueira-Coutinho et al., 2015). Consequently, the corrective makeup may be considered to have a wide spectrum UVA photoprotection, since they presented $\lambda \mathrm{c}$ values varying from 378 to $380 \mathrm{~nm}$, while the non-pigmented emulsive bases NPB1 and NPB2 may be classified as having intermediate protection against UVA radiation (358 and $361 \mathrm{~nm}$, respectively).

\section{Determination of the photostability of NPB2 base and corrective makeup}

The photostability of chemical sunscreens is important because it influences the effectiveness of sunscreens and their inability to generate toxic products in the skin (Kockler et al., 2012).

The SPF values before and after sun exposure were expressed as means \pm standard deviations (Table VII). These results indicated that the SPF values were not statistically different $(p>0.05)$ before and after exposure in the case of both NPB2 base and corrective makeup.

TABLE VI - SPF values, UVA/UVB ratios and critical wavelengths $(\lambda c)$ obtained by transmittance spectrophotometry

\begin{tabular}{ccccc}
\hline $\begin{array}{c}\text { Photoprotective } \\
\text { Formulations }\end{array}$ & SPF in vitro & $\begin{array}{c}\text { UVA/UVB Ratio (initial } \\
\text { mean) }\end{array}$ & $\begin{array}{c}\text { UVA/UVB Ratio } \\
\text { (post exposure mean) }\end{array}$ & $\begin{array}{c}\text { Critical Wavelength } \\
(\boldsymbol{\lambda} \mathbf{c})\end{array}$ \\
\hline NPB1 & $27.85 \pm 7.68$ & 0.41 & 0.39 & 358 \\
NPB2 & $28.74 \pm 6.86$ & 0.41 & 0.40 & 361 \\
BEIGE I & $28.81 \pm 5.11$ & 0.56 & 0.55 & 378 \\
BEIGE II & $28.51 \pm 5.41$ & 0.53 & 0.50 & 378 \\
BEIGE III & $27.85 \pm 4.43$ & 0.52 & 0.51 & 380 \\
BRONZE & $29.29 \pm 6.40$ & 0.52 & 0.51 & 378 \\
TAN & $29.33 \pm 6.44$ & 0.51 & 0.50 & 379 \\
\hline
\end{tabular}

TABLE VII - SPF values of each photoprotective formulation, before and after $2 \mathrm{~h}, 4 \mathrm{~h}$ and $6 \mathrm{~h}$ of sun exposure, obtained by transmittance spectrophotometry using integrating sphere (Labsphere ${ }^{\circledR}$ )

\begin{tabular}{ccccc}
\hline $\begin{array}{c}\text { Photoprotective } \\
\text { Formulation }\end{array}$ & $\begin{array}{c}\text { SPF before } \\
\text { of sun exposure }\end{array}$ & $\begin{array}{c}\text { SPF after } \mathbf{2} \mathbf{h} \\
\text { of sun exposure }\end{array}$ & $\begin{array}{c}\text { SPF after } \mathbf{4} \mathbf{h} \\
\text { of sun exposure }\end{array}$ & $\begin{array}{c}\text { SPF after } \mathbf{6} \mathbf{h} \\
\text { of sun exposure }\end{array}$ \\
\hline NPB2 & $29.55 \pm 4.84$ & $26.55 \pm 3.13$ & $26.11 \pm 3.98$ & $25.22 \pm 1.64$ \\
BEIGE I & $29.59 \pm 3.35$ & $28.88 \pm 3.68$ & $27.37 \pm 2.80$ & $25.55 \pm 4.16$ \\
BEIGE II & $29.25 \pm 3.12$ & $27.55 \pm 4.80$ & $27.18 \pm 1.54$ & $27.07 \pm 3.96$ \\
BEIGE III & $29.62 \pm 2.69$ & $28.44 \pm 1.66$ & $27.88 \pm 4.19$ & $26.22 \pm 3.15$ \\
BRONZE & $30.14 \pm 2.03$ & $27.66 \pm 3.70$ & $26.77 \pm 1.09$ & $26.11 \pm 1.69$ \\
TAN & $30.33 \pm 2.87$ & $28.11 \pm 3.37$ & $26.66 \pm 2.64$ & $26.44 \pm 3.32$ \\
\hline
\end{tabular}


The assessment of the percentage effectiveness $\left(\% \mathrm{FPS}_{\text {eff }}\right)$ for each sample was performed after sun exposure as a parameter of photostability in relation to the absolute values of SPF (Garoli et al., 2008; Hojerová, Medovcíková, Mikula, 2011) (Table VIII).

TABLE VIII - Percentage effectiveness ( $\left.\% \mathrm{SPF}_{\text {eff }}\right)$ after sun exposure of NPB2 base and corrective makeup

\begin{tabular}{ccc}
\hline $\begin{array}{c}\text { Photoprotective } \\
\text { Formulations }\end{array}$ & \%SPF $_{\text {eff }}$ & $\begin{array}{c}\text { Percentage effectiveness } \\
\text { considering the min. and } \\
\text { max. SD(s) }\end{array}$ \\
\hline NPB2 2 h & 89.84 & 86.29 to 94.78 \\
NPB2 4 h & 88.35 & 87.50 to 89.54 \\
NPB2 6 h & 87.98 & 82.27 to 95.94 \\
BEGE I 2 h & 97.60 & 96.04 to 98.84 \\
BEGE I 4 h & 92.49 & 91.58 to 93.63 \\
BEGE I 6 h & 86.34 & 81.52 to 90.18 \\
BEGE II 2 h & 94.18 & 87.07 to 99.93 \\
BEGE II 4 h & 92.92 & 88.73 to 98.10 \\
BEGE II 6 h & 92.54 & 88.44 to 95.86 \\
BEGE III 2 h & 96.01 & 93.17 to 99.42 \\
BEGE III 4 h & 94.12 & 87.94 to 99.27 \\
BEGE III 6 h & 88.52 & 85.65 to 90.90 \\
BRONZE 2 h & 91.77 & 85.21 to 97.49 \\
BRONZE 4 h & 88.81 & 86.60 to 91.35 \\
BRONZE 6 h & 86.62 & 86.41 to 86.87 \\
TAN 2 h & 92.68 & 90.08 to 94.82 \\
TAN 4 h & 87.89 & 87.44 to 88.27 \\
TAN 6 h & 87.17 & 84.18 to 89.64 \\
\hline SDD - Standar Devi &
\end{tabular}

All samples may be considered photostable because they displayed SPF variations $<20 \%$. Although the standard deviations varied, the SPF percentage variations were $<20 \%$ for all samples, with the minimum and maximum $\left(\% \mathrm{FPS}_{\text {eff }}\right)$ for all samples exceeding $80 \%$. This result demonstrates the photostability of the tested products. Furthermore, the results showed that the presence of pigments in the makeup did not cause significant differences in photostability compared to nonpigmented NPB2 formulation.

The UVA/UVB ratio values before and after sun exposure are presented in Table IX.

The UVA/UVB ratio percentage changes provided further evidence for the photostability of the formulations. All values were $<20 \%$.

Considering the results of SPF and UVA/UVB ratio analysis, the NPB2 base and corrective makeup appear to be photostable against UVB and UVA radiation.

\section{Stability and physicochemical tests}

In the accelerated stability test, we aimed to predict the stability of the product, its lifespan, and its compatibility with packaging materials (Anvisa, 2004). The parameters to be analyzed when testing the stability of a product are determined by the formulator. Furthermore, they depend on the product being examined and the components used in the formulation (Anvisa, 2004; Clares et al., 2011; Smaoui et al., 2013).

\section{Organoleptic characteristics (appearance, color, and odor)}

The NPB2 base had a fine texture, little brightness, dry feel, homogeneous aspect, slightly yellowish color, and particular odor before stability analysis. The different

TABLE IX - UVA/UVB ratios of each photoprotective formulation, before and after $2 \mathrm{~h}, 4 \mathrm{~h}$ and $6 \mathrm{~h}$ of sun exposure, obtained by transmittance spectrophotometry and the calculation of the percentage variation of the UVA/UVB ratio after each period of sun exposure

\begin{tabular}{cccccccc}
\hline Formulations & $\begin{array}{c}\text { UVA/UVB } \\
\text { ratio before of } \\
\text { sun exposure }\end{array}$ & $\begin{array}{c}\text { UVA/UVB } \\
\text { ratio after } \\
\mathbf{2} \text { h of sun } \\
\text { exposure }\end{array}$ & $\begin{array}{c}\text { Percentage } \\
\text { variation }\end{array}$ & $\begin{array}{c}\text { UVA/UVB } \\
\text { ratio after } \\
\text { 4 h of sun } \\
\text { exposure }\end{array}$ & $\begin{array}{c}\text { Percentage } \\
\text { variation }\end{array}$ & $\begin{array}{c}\text { UVA/UVB } \\
\text { ratio after } \\
\text { 6 h of sun } \\
\text { exposure }\end{array}$ & $\begin{array}{c}\text { Percentage } \\
\text { variation }\end{array}$ \\
\hline NPB2 & 0.40 & 0.39 & 2.50 & 0.37 & 7.50 & 0.36 & 10.00 \\
BEIGE I & 0.54 & 0.52 & 3.70 & 0.51 & 5.55 & 0.50 & 7.40 \\
BEIGE II & 0.49 & 0.47 & 4.08 & 0.45 & 8.16 & 0.44 & 10.20 \\
BEIGE III & 0.52 & 0.50 & 3.84 & 0.49 & 5.77 & 0.46 & 11.54 \\
BRONZE & 0.50 & 0.48 & 4.00 & 0.47 & 6.00 & 0.45 & 10.00 \\
TAN & 0.49 & 0.48 & 3.04 & 0.47 & 4.08 & 0.45 & 8.16 \\
\hline
\end{tabular}


kinds of corrective makeup had similar features, and only varied in color. The NPB2 base remained stable throughout the stability study period, with its organoleptic characteristics unchanged.

After 90 days, all samples of corrective makeup remained stable in terms of odor regardless of the temperature at which they had been stored. All corrective makeup types analyzed showed little separation of the pigments from the emulsive base. Separation was observed only from the $15^{\text {th }}$ test day at room temperature and in the greenhouse, while in a fridge, separation occurred only from the $30^{\text {th }}$ day. The separation of photoprotective emulsions phases was not verified regardless of the temperature at which they were stored. All samples regained their homogeneous aspect and original color after agitation, demonstrating that agitation will be necessary before applying the formulations to the skin.

\section{Centrifugation, $\mathrm{pH}$, and density}

Changes in the $\mathrm{pH}$ of an emulsion may indicate chemical alterations in the formulation (Anvisa, 2004; Clares et al., 2011; Smaoui et al., 2013).

The results of the determination of the density of semi-solid emulsions sample may indicate a possible incorporation of air or the loss of volatile ingredients (Anvisa, 2004; Clares et al., 2011; Smaoui et al., 2013).

The results of centrifugation assessment, $\mathrm{pH}$ assessment, and density analysis in NPB2, BEIGE I, BEIGE II, BEIGE III, BRONZE, and TAN formulations stored at room temperature $\left(23.0 \pm 2.0^{\circ} \mathrm{C}\right)$, in a greenhouse $\left(37.0 \pm 2.0^{\circ} \mathrm{C}\right)$, or in a fridge $\left(5.0 \pm 2.0^{\circ} \mathrm{C}\right)$ for up to 90 days are presented in Tables X to XII.

No evidence of instability was found in the centrifugation tests in the NPB2 base samples, regardless of the storage temperature used. In all trials of centrifugation, samples of corrective makeup displayed pigments separation. However, the emulsive base remained stable regardless of the temperature at which the samples were stored. When all samples were agitated, they regained their homogenous aspect.

The $\mathrm{pH}$ of all formulations analyzed varied between 6.6 and 7.0 over the $90 \mathrm{~d}$ period of the study. A pH of slightly acid to neutral is desirable in formulations for dermocosmetic use to preserve the natural balance of the skin.

Small changes in $\mathrm{pH}$ did not appear to contribute to instability, since no evidence of instability in the emulsions during macroscopic aspect exams and centrifuge tests was found.

TABLE X - Results of centrifugation tests (Centrif.), pH and density (Dens.) of the NPB2 base and corrective makeup stored at room temperature $\left(23.0 \pm 2.0^{\circ} \mathrm{C}\right)$ for up to 90 days

\begin{tabular}{|c|c|c|c|c|c|c|c|c|c|}
\hline \multicolumn{10}{|c|}{ FORMULATIONS } \\
\hline \multirow{2}{*}{$\begin{array}{c}\text { Time } \\
\text { (days) }\end{array}$} & \multicolumn{3}{|c|}{ NPB2 } & \multicolumn{3}{|c|}{ BEIGE I } & \multicolumn{3}{|c|}{ BEIGE II } \\
\hline & Centrif. $^{1}$ & pH & Dens. & Centrif. $^{1}$ & pH & Dens. & Centrif. $^{1}$ & pH & Dens. \\
\hline 0 & 1 & 6.90 & 1.034 & 2 & 6.96 & 1.124 & 2 & 6.98 & 1.124 \\
\hline 7 & 1 & 6.82 & 1.034 & 2 & 6.98 & 1.120 & 2 & 6.85 & 1.124 \\
\hline 15 & 1 & 6.88 & 1.034 & 2 & 6.95 & 1.119 & 2 & 6.98 & 1.121 \\
\hline 30 & 1 & 6.94 & 1.034 & 2 & 6.99 & 1.122 & 2 & 6.92 & 1.124 \\
\hline 60 & 1 & 6.95 & 1.034 & 2 & 7.00 & 1.121 & 2 & 6.87 & 1.124 \\
\hline 90 & 1 & 6.97 & 1.034 & 2 & 6.98 & 1.121 & 2 & 6.87 & 1.124 \\
\hline \multirow{2}{*}{$\begin{array}{c}\text { Time } \\
\text { (days) }\end{array}$} & \multicolumn{3}{|c|}{ BEIGE III } & \multicolumn{3}{|c|}{ BRONZE } & \multicolumn{3}{|c|}{ TAN } \\
\hline & Centrif. ${ }^{1}$ & pH & Dens. & Centrif. $^{1}$ & pH & Dens. & Centrif. $^{1}$ & $\mathbf{p H}$ & Dens. \\
\hline 0 & 2 & 6.96 & 1.113 & 2 & 6.77 & 1.117 & 2 & 6.80 & 1.131 \\
\hline 7 & 2 & 6.81 & 1.120 & 2 & 6.79 & 1.117 & 2 & 6.79 & 1.128 \\
\hline 15 & 2 & 6.88 & 1.110 & 2 & 6.88 & 1.118 & 2 & 6.88 & 1.129 \\
\hline 30 & 2 & 6.88 & 1.114 & 2 & 6.83 & 1.118 & 2 & 6.85 & 1.126 \\
\hline 60 & 2 & 6.85 & 1.119 & 2 & 6.77 & 1.118 & 2 & 6.79 & 1.127 \\
\hline 90 & 2 & 6.87 & 1.121 & 2 & 6.76 & 1.118 & 2 & 6.77 & 1.128 \\
\hline
\end{tabular}

(1) 1 - No visible changes; 2 - Slight evidence of lack homogeneity; 3 - Beginning of phase separation; 4 - Clear separation of phases; 5 - Total separation of phases 
TABLE XI - Results of centrifugation tests (Centrif.), $\mathrm{pH}$ and density (Dens.) of the NPB2 base and corrective makeup stored at $37.0 \pm 2.0^{\circ} \mathrm{C}$ for up to 90 days

\begin{tabular}{|c|c|c|c|c|c|c|c|c|c|}
\hline \multicolumn{10}{|c|}{ FORMULATIONS } \\
\hline \multirow{2}{*}{$\begin{array}{c}\text { Time } \\
\text { (days) }\end{array}$} & \multicolumn{3}{|c|}{ NPB2 } & \multicolumn{3}{|c|}{ BEIGE I } & \multicolumn{3}{|c|}{ BEIGE II } \\
\hline & Centrif. $^{1}$ & pH & Dens. & Centrif. ${ }^{1}$ & pH & Dens. & Centrif. ${ }^{1}$ & $\mathrm{pH}$ & Dens. \\
\hline 0 & - & - & - & - & - & - & - & - & - \\
\hline 7 & 2 & 6.81 & 1.035 & 2 & 6.85 & 1.117 & 2 & 6.83 & 1.124 \\
\hline 15 & 2 & 6.88 & 1.034 & 2 & 6.82 & 1.122 & 2 & 7.00 & 1.118 \\
\hline 30 & 2 & 6.82 & 1.035 & 2 & 6.97 & 1.121 & 2 & 6.94 & 1.121 \\
\hline 60 & 2 & 6.82 & 1.034 & 2 & 6.83 & 1.119 & 2 & 6.93 & 1.124 \\
\hline 90 & 2 & 6.89 & 1.034 & 2 & 7.00 & 1.121 & 2 & 6.92 & 1.123 \\
\hline \multirow{2}{*}{$\begin{array}{c}\text { Time } \\
\text { (days) }\end{array}$} & \multicolumn{3}{|c|}{ BEIGE III } & \multicolumn{3}{|c|}{ BRONZE } & \multicolumn{3}{|c|}{ TAN } \\
\hline & Centrif. ${ }^{1}$ & pH & Dens. & Centrif. ${ }^{1}$ & pH & Dens. & Centrif. $^{1}$ & $\mathrm{pH}$ & Dens. \\
\hline 0 & - & - & - & - & - & - & - & - & - \\
\hline 7 & 2 & 6.83 & 1.125 & 2 & 6.80 & 1.117 & 2 & 6.81 & 1.128 \\
\hline 15 & 2 & 6.94 & 1.121 & 2 & 6.77 & 1.117 & 2 & 6.85 & 1.127 \\
\hline 30 & 2 & 6.91 & 1.121 & 2 & 6.82 & 1.118 & 2 & 6.85 & 1.126 \\
\hline 60 & 2 & 6.86 & 1.119 & 2 & 6.67 & 1.118 & 2 & 6.63 & 1.126 \\
\hline 90 & 2 & 6.84 & 1.121 & 2 & 6.68 & 1.118 & 2 & 6.69 & 1.127 \\
\hline
\end{tabular}

(1) 1 - No visible changes; 2 - Slight evidence of lack homogeneity; 3 - Beginning of phase separation; 4 - Clear separation of phases; 5 - Total separation of phases.

TABLE XII - Results of centrifugation tests (Centrif.), $\mathrm{pH}$ and density (Dens.) of the NPB2 base and corrective makeup stored at $5.0 \pm 2.0^{\circ} \mathrm{C}$ for up to 90 days

\begin{tabular}{|c|c|c|c|c|c|c|c|c|c|}
\hline \multicolumn{10}{|c|}{ FORMULATIONS } \\
\hline \multirow{2}{*}{$\begin{array}{l}\text { Time } \\
\text { (days) }\end{array}$} & \multicolumn{3}{|c|}{ NPB2 } & \multicolumn{3}{|c|}{ BEIGE I } & \multicolumn{3}{|c|}{ BEIGE II } \\
\hline & Centrif. ${ }^{1}$ & pH & Dens. & Centrif. ${ }^{1}$ & pH & Dens. & Centrif. ${ }^{1}$ & $\mathrm{pH}$ & Dens. \\
\hline 0 & - & - & - & - & - & - & - & - & - \\
\hline 7 & 2 & 6.89 & 1.034 & 2 & 6.99 & 1.124 & 2 & 6.83 & 1.125 \\
\hline 15 & 2 & 6.84 & 1.036 & 2 & 6.98 & 1.122 & 2 & 6.92 & 1.123 \\
\hline 30 & 2 & 6.92 & 1.035 & 2 & 6.99 & 1.122 & 2 & 6.98 & 1.123 \\
\hline 60 & 2 & 6.96 & 1.034 & 2 & 6.85 & 1.123 & 2 & 6.88 & 1.124 \\
\hline 90 & 2 & 6.96 & 1.035 & 2 & 6.97 & 1.122 & 2 & 6.90 & 1.124 \\
\hline \multirow{2}{*}{$\begin{array}{c}\text { Time } \\
\text { (days) }\end{array}$} & \multicolumn{3}{|c|}{ BEIGE III } & \multicolumn{3}{|c|}{ BRONZE } & \multicolumn{3}{|c|}{ TAN } \\
\hline & Centrif. $^{1}$ & pH & Dens. & Centrif. ${ }^{1}$ & pH & Dens. & Centrif. $^{1}$ & $\mathrm{pH}$ & Dens. \\
\hline 0 & - & - & - & - & - & - & - & - & - \\
\hline 7 & 2 & 6.88 & 1.114 & 2 & 6.79 & 1.117 & 2 & 6.82 & 1.129 \\
\hline 15 & 2 & 6.92 & 1.117 & 2 & 6.83 & 1.118 & 2 & 6.84 & 1.128 \\
\hline 30 & 2 & 6.93 & 1.117 & 2 & 6.84 & 1.118 & 2 & 6.87 & 1.127 \\
\hline 60 & 2 & 6.87 & 1.120 & 2 & 6.79 & 1.118 & 2 & 6.78 & 1.126 \\
\hline 90 & 2 & 6.87 & 1.119 & 2 & 6.76 & 1.118 & 2 & 6.76 & 1.127 \\
\hline
\end{tabular}

(1) 1 - No visible changes; 2 - Slight evidence of lack homogeneity; 3 - Beginning of phase separation; 4 - Clear separation of phases; 5 - Total separation of phases. 
The density of the NPB2 base samples remained stable at $1.03 \mathrm{~g} / \mathrm{mL}$ regardless of storage temperature, while the corrective makeup densities ranged from 1.11 to $1.13 \mathrm{~g} / \mathrm{mL}$, also appearing to be stable. These results suggest that there was no loss of volatile ingredients or the incorporation of air into the formulations.

\section{Variations in SPF}

Analysis of the variation in SPF during stability tests was performed by transmittance spectrophotometry. The SPF variation assessment results of the NPB2 formulation and corrective makeup stored at room temperature $\left(23.0 \pm 2.0^{\circ} \mathrm{C}\right)$, in a greenhouse $\left(37.0 \pm 2.0^{\circ} \mathrm{C}\right)$, and in a fridge $\left(5.0 \pm 2.0^{\circ} \mathrm{C}\right)$ for up to $90 \mathrm{~d}$ are presented in Tables XIII to XV.

The results indicated that all SPF values found were not statistically different $(\mathrm{p}>0.05)$ between the nonpigmented base NPB2 and corrective makeup. Therefore,

TABLE XIII - Results of SPF variation tests of the NPB2 base and corrective makeup stored at room temperature $\left(23.0 \pm 2.0^{\circ} \mathrm{C}\right)$ for up to 90 days

\begin{tabular}{|c|c|c|c|c|c|c|}
\hline \multicolumn{7}{|c|}{ FORMULATIONS } \\
\hline \multirow{2}{*}{ Time (days) } & NPB2 & BEIGE I & BEIGE II & BEIGE III & BRONZE & TAN \\
\hline & $\mathrm{SPF}^{1} \pm \mathrm{SD}$ & $\mathrm{SPF}^{1} \pm \mathrm{SD}$ & $\mathrm{SPF}^{1} \pm \mathrm{SD}$ & $\mathrm{SPF}^{1} \pm \mathrm{SD}$ & $\mathrm{SPF}^{1} \pm \mathrm{SD}$ & $\mathrm{SPF}^{1} \pm \mathrm{SD}$ \\
\hline 0 & $28.74 \pm 6.86$ & $28.81 \pm 5.11$ & $28.51 \pm 5.41$ & $27.85 \pm 4.43$ & $29.29 \pm 6.40$ & $29.33 \pm 6.44$ \\
\hline 7 & $27.25 \pm 7.67$ & $28.81 \pm 7.28$ & $27.81 \pm 3.60$ & $28.22 \pm 5.52$ & $29.18 \pm 3.28$ & $29.33 \pm 3.14$ \\
\hline 15 & $28.25 \pm 6.32$ & $28.40 \pm 5.33$ & $29.07 \pm 6.98$ & $28.74 \pm 4.60$ & $28.33 \pm 3.98$ & $29.00 \pm 3.54$ \\
\hline 30 & $28.40 \pm 6.27$ & $28.14 \pm 4.16$ & $31.96 \pm 3.39$ & $29.11 \pm 2.79$ & $29.74 \pm 4.16$ & $29.40 \pm 2.93$ \\
\hline 60 & $30.66 \pm 1.71$ & $28.55 \pm 2.15$ & $30.70 \pm 3.23$ & $28.81 \pm 3.26$ & $30.22 \pm 3.36$ & $29.40 \pm 3.69$ \\
\hline 90 & $28.29 \pm 2.81$ & $28.85 \pm 4.83$ & $29.77 \pm 3.32$ & $29.25 \pm 2.33$ & $29.14 \pm 3.02$ & $29.07 \pm 2.41$ \\
\hline
\end{tabular}

(1) Mean of three determinations; SD: Standard Deviation

TABLE XIV - Results of SPF variation tests of the NPB2 base and corrective makeup stored at $37.0 \pm 2.0^{\circ} \mathrm{C}$ for up to 90 days

\begin{tabular}{|c|c|c|c|c|c|c|}
\hline \multicolumn{7}{|c|}{ FORMULATIONS } \\
\hline \multirow{2}{*}{ Time (days) } & NPB2 & BEIGE I & BEIGE II & BEIGE III & BRONZE & TAN \\
\hline & $\mathrm{SPF}^{1} \pm \mathrm{SD}$ & $\mathrm{SPF}^{1} \pm \mathrm{SD}$ & $\mathrm{SPF}^{1} \pm \mathrm{SD}$ & $\mathrm{SPF}^{1} \pm \mathrm{SD}$ & $\mathrm{SPF}^{1} \pm \mathrm{SD}$ & $\mathrm{SPF}^{1} \pm \mathrm{SD}$ \\
\hline 0 & - & - & - & - & - & - \\
\hline 7 & $29.03 \pm 6.11$ & $29.33 \pm 4.37$ & $29.70 \pm 5.41$ & $28.33 \pm 5.73$ & $29.25 \pm 2.34$ & $28.96 \pm 3.39$ \\
\hline 15 & $28.40 \pm 6.12$ & $29.25 \pm 8.03$ & $27.14 \pm 4.47$ & $28.81 \pm 5.83$ & $28.96 \pm 3.78$ & $30.33 \pm 3.64$ \\
\hline 30 & $27.14 \pm 6.49$ & $27.29 \pm 3.52$ & $29.44 \pm 3.78$ & $32.29 \pm 2.26$ & $29.51 \pm 3.32$ & $29.11 \pm 3.22$ \\
\hline 60 & $29.37 \pm 4.94$ & $29.88 \pm 3.36$ & $28.62 \pm 3.21$ & $29.11 \pm 2.50$ & $29.81 \pm 2.54$ & $29.70 \pm 3.29$ \\
\hline 90 & $30.44 \pm 4.77$ & $31.48 \pm 4.15$ & $28.44 \pm 3.00$ & $30.62 \pm 2.84$ & $28.59 \pm 1.82$ & $29.33 \pm 2.07$ \\
\hline
\end{tabular}

(1) Mean of three determinations; SD: Standard Deviation.

TABLE XV - Results of SPF variation tests of the NPB2 base and corrective makeup stored at $5.0 \pm 2.0^{\circ} \mathrm{C}$ for up to 90 days

\begin{tabular}{|c|c|c|c|c|c|c|}
\hline \multicolumn{7}{|c|}{ FORMULATIONS } \\
\hline \multirow{2}{*}{ Time (days) } & NPB2 & BEIGE I & BEIGE II & BEIGE III & BRONZE & TAN \\
\hline & $\mathrm{SPF}^{1} \pm \mathrm{SD}$ & $\mathrm{SPF}^{1} \pm \mathrm{SD}$ & $\mathrm{SPF}^{1} \pm \mathrm{SD}$ & $\mathrm{SPF}^{1} \pm \mathrm{SD}$ & $\mathrm{SPF}^{1} \pm \mathrm{SD}$ & $\mathrm{SPF}^{1} \pm \mathrm{SD}$ \\
\hline 0 & - & - & - & - & - & - \\
\hline 7 & $28.18 \pm 6.10$ & $30.18 \pm 4.22$ & $27.85 \pm 5.42$ & $28.74 \pm 6.52$ & $29.48 \pm 3.19$ & $28.92 \pm 2.47$ \\
\hline 15 & $28.37 \pm 6.77$ & $28.18 \pm 6.06$ & $28.62 \pm 4.76$ & $28.74 \pm 3.87$ & $29.18 \pm 3.99$ & $30.25 \pm 2.71$ \\
\hline 30 & $29.66 \pm 4.91$ & $29.74 \pm 6.39$ & $27.70 \pm 3.99$ & $29.18 \pm 2.60$ & $29.11 \pm 3.58$ & $29.62 \pm 3.49$ \\
\hline 60 & $28.66 \pm 3.22$ & $29.55 \pm 4.21$ & $31.59 \pm 2.66$ & $28.14 \pm 2.76$ & $28.33 \pm 3.78$ & $30.07 \pm 3.24$ \\
\hline 90 & $30.11 \pm 3.61$ & $31.62 \pm 3.64$ & $28.48 \pm 3.20$ & $29.18 \pm 2.81$ & $29.37 \pm 2.17$ & $28.92 \pm 2.52$ \\
\hline
\end{tabular}

(1) Mean of three determinations; SD: Standard Deviation 
the statistical analyses suggested that the pigments did not influence changes in SPF of the corrective makeup.

According to Anvisa (2012), and considering the standard deviations found in this study, all samples remained in the category of average-high photoprotection regardless of the temperature at which they were stored.

\section{Determination of the spreadability of NPB2 base and corrective makeup}

Spreadability can be defined as the expansion of a formulation on a surface after a certain period of time, and it is closely linked to applying these formulations at the site of action. Therefore, sunscreens should allow easy spreading on the skin to ensure nominal SPF (Nesseem, 2011; Deuschle et al., 2015). The results are presented in Table XVI, where MD is the mean diameter. For each sequence of measurements obtained, spreadability in $\left(\mathrm{mm}^{2}\right)$ and standard deviation (SD) were assessed.

The results showed that all corrective makeup and the non-pigmented base NPB2 displayed statistically equal spreadability profiles $(\mathrm{p}>0.05)$, indicating that the presence of pigments did not affect the spreadability profile of the emulsive base.

\section{Determination of occlusive effect of the developed formulations}

The tests for determining the occlusive effect allowed to verify the capacity of the formulations to maintain skin hydration. Applying occlusive products forms a film on the skin, and prevents the evaporation of

TABLE XVI - Results obtained from the spreadability test with the emulsive base NPB2 and corrective makeup

\begin{tabular}{|c|c|c|c|c|c|}
\hline \multicolumn{6}{|c|}{ NON-PIGMENTED BASE (NPB2) } \\
\hline $\begin{array}{l}\text { Weight } \\
\text { (gram) }\end{array}$ & $\begin{array}{c}\text { Sample } 1 \\
(\mathrm{~mm})\end{array}$ & $\begin{array}{c}\text { Sample } 2 \\
(\mathrm{~mm})\end{array}$ & $\begin{array}{c}\text { Sample } 3 \\
(\mathrm{~mm})\end{array}$ & $\begin{array}{c}\text { MD } \\
(\mathbf{m m})\end{array}$ & $\begin{array}{c}\text { Spreadability } \\
\left(\mathbf{m m}^{2}\right) \pm \text { SD }\end{array}$ \\
\hline 5.1 & 14 & 14 & 15 & 14.33 & $161.44 \pm 13.14$ \\
\hline 7.1 & 16 & 16 & 16 & 16.00 & $200.96 \pm 0.00$ \\
\hline 9.1 & 17 & 18 & 17 & 17.00 & $236.02 \pm 15.86$ \\
\hline 14.1 & 19 & 20 & 20 & 19.67 & $303.79 \pm 17.67$ \\
\hline \multicolumn{6}{|c|}{ BEIGE I } \\
\hline $\begin{array}{l}\text { Weight } \\
\text { (gram) }\end{array}$ & $\begin{array}{c}\text { Sample } 1 \\
(\mathrm{~mm})\end{array}$ & $\begin{array}{c}\text { Sample } 2 \\
(\mathrm{~mm})\end{array}$ & $\begin{array}{c}\text { Sample } 3 \\
(\mathrm{~mm})\end{array}$ & $\begin{array}{c}\text { MD } \\
(\mathbf{m m})\end{array}$ & $\begin{array}{c}\text { Spreadability } \\
\left(\mathbf{m m}^{2}\right) \pm \text { SD }\end{array}$ \\
\hline 5.1 & 15 & 14 & 14 & 14.33 & $161.44 \pm 13.14$ \\
\hline 7.1 & 16 & 16 & 15 & 15.67 & $192.84 \pm 14.05$ \\
\hline 9.1 & 18 & 17 & 17 & 17.33 & $236.02 \pm 15.86$ \\
\hline 14.1 & 20 & 19 & 19 & 19.33 & $293.59 \pm 17.67$ \\
\hline \multicolumn{6}{|c|}{ BEIGE II } \\
\hline $\begin{array}{l}\text { Weight } \\
\text { (gram) }\end{array}$ & $\begin{array}{c}\text { Sample } 1 \\
(\mathrm{~mm})\end{array}$ & $\begin{array}{c}\text { Sample } 2 \\
(\mathrm{~mm})\end{array}$ & $\begin{array}{c}\text { Sample } 3 \\
(\mathrm{~mm})\end{array}$ & $\begin{array}{c}\text { MD } \\
(\mathbf{m m})\end{array}$ & $\begin{array}{c}\text { Spreadability } \\
\left(\mathbf{m m}^{2}\right) \pm \text { SD }\end{array}$ \\
\hline 5.1 & 15 & 15 & 14 & 14.67 & $169.03 \pm 13.14$ \\
\hline 7.1 & 16 & 16 & 16 & 16.00 & $200.96 \pm 0.00$ \\
\hline 9.1 & 18 & 18 & 17 & 17.67 & $245.18 \pm 15.86$ \\
\hline 14.1 & 20 & 19 & 20 & 19.67 & $303.79 \pm 17.67$ \\
\hline \multicolumn{6}{|c|}{ BEIGE III } \\
\hline $\begin{array}{l}\text { Weight } \\
\text { (gram) }\end{array}$ & $\begin{array}{c}\text { Sample } 1 \\
(\mathrm{~mm})\end{array}$ & $\begin{array}{c}\text { Sample } 2 \\
(\mathrm{~mm})\end{array}$ & $\begin{array}{c}\text { Sample } 3 \\
(\mathbf{m m})\end{array}$ & $\begin{array}{c}\text { MD } \\
(\mathbf{m m})\end{array}$ & $\begin{array}{c}\text { Spreadability } \\
\left(\mathbf{m m}^{2}\right) \pm \text { SD }\end{array}$ \\
\hline 5.1 & 15 & 15 & 15 & 15.00 & $176.62 \pm 0.00$ \\
\hline 7.1 & 16 & 16 & 16 & 16.00 & $200.96 \pm 0.00$ \\
\hline 9.1 & 18 & 18 & 18 & 18.00 & $254.34 \pm 0.00$ \\
\hline 14.1 & 20 & 20 & 19 & 19.67 & $303.79 \pm 17.67$ \\
\hline
\end{tabular}


Multifunctional photoprotection: corrective makeup for cutaneous dyschromias

TABLE XVI - Results obtained from the spreadability test with the emulsive base NPB2 and corrective makeup (cont.)

\begin{tabular}{|c|c|c|c|c|c|}
\hline \multicolumn{6}{|c|}{ BRONZE } \\
\hline $\begin{array}{l}\text { Weight } \\
\text { (gram) }\end{array}$ & $\begin{array}{c}\text { Sample } 1 \\
(\mathrm{~mm})\end{array}$ & $\begin{array}{c}\text { Sample } 2 \\
(\mathrm{~mm})\end{array}$ & $\begin{array}{c}\text { Sample } 3 \\
(\mathrm{~mm})\end{array}$ & $\begin{array}{c}\text { MD } \\
(\mathbf{m m})\end{array}$ & $\begin{array}{c}\text { Spreadability } \\
\left(\mathbf{m m}^{2}\right) \pm \text { SD }\end{array}$ \\
\hline 5.1 & 14 & 15 & 14 & 14.33 & $161.44 \pm 13.14$ \\
\hline 7.1 & 15 & 16 & 16 & 15.67 & $192.84 \pm 14.05$ \\
\hline 9.1 & 17 & 18 & 17 & 17.33 & $236.02 \pm 15.86$ \\
\hline 14.1 & 19 & 20 & 19 & 19.33 & $293.59 \pm 17.67$ \\
\hline \multicolumn{6}{|c|}{ TAN } \\
\hline $\begin{array}{l}\text { Weight } \\
\text { (gram) }\end{array}$ & $\begin{array}{c}\text { Sample } 1 \\
(\mathrm{~mm})\end{array}$ & $\begin{array}{c}\text { Sample } 2 \\
(\mathrm{~mm})\end{array}$ & $\begin{array}{c}\text { Sample } 3 \\
(\mathrm{~mm})\end{array}$ & $\begin{array}{c}\text { MD } \\
(\mathbf{m m})\end{array}$ & $\begin{array}{c}\text { Spreadability } \\
\left(\mathbf{m m}^{2}\right) \pm \text { SD }\end{array}$ \\
\hline 5.1 & 15 & 14 & 14 & 14.33 & $161.44 \pm 13.14$ \\
\hline 7.1 & 16 & 15 & 15 & 15.33 & $184.73 \pm 14.05$ \\
\hline 9.1 & 18 & 17 & 17 & 17.33 & $236.02 \pm 15.86$ \\
\hline 14.1 & 20 & 19 & 19 & 19.33 & $293.59 \pm 17.67$ \\
\hline
\end{tabular}

MD: Mean Diameter; SD: Standard Deviation.

water to the atmosphere. Water is thus retained in the skin (Teeranachaideekul et al., 2008).

A zero $\mathrm{F}$ (occlusion factor) value means that no occlusive effect in comparison with the reference was observed, whereas an $\mathrm{F}$ value of 100 indicated maximum occlusivity of the formulation. The $\mathrm{F}$ values and standard deviations found after 6,24 , and 48 hours are presented in Table XVII.

The results showed that after $6 \mathrm{~h}$, all corrective makeup had statistically equal $F$ values $(p>0.05)$. In the case of NPB2 base, the F value was statistically lower than that of the corrective makeup $(\mathrm{p}<0.05)$. Similarly, F value of the NPB2 base was statistically higher than that of the NPB1 base $(\mathrm{p}<0.05)$.

However, after $24 \mathrm{~h}$, the F value of the NPB2 base was not statistically different to that of the corrective makeup ( $p>0.05)$. The corrective makeup and NPB2 base showed $F$ values significantly higher to that of the NPB1 base $(p<0.05)$. The same profile of the occlusive effect was found after $48 \mathrm{~h}$.

The results showed that the incorporation of methylmethacrylate crosspolymer, the polymer aluminum starch octenylsuccinate, and pigments caused a significant increase of the occlusive effect of formulations, increasing their capacity to maintain the hydration level of the skin.

\section{CONCLUSIONS}

The corrective photoprotective makeup developed in this study featured a fine texture, little brightness, a homogeneous aspect and dry to the touch. The corrective makeup was photostable under sun light and stable in terms of their physicochemical and organoleptic characteristics.

Solar radiation can be very harmful to the human body. This is especially true in individuals with skin diseases, who are very susceptible to cutaneous neoplasia. Using sunscreen is necessary to ensure the health and quality of life of patients with dermatosis characterized by alteration of the skin pigmentation. The product developed and tested in this study has the advantage of feature an average-to-high UVB photoprotective activity, and good photoprotective activity with a broad spectrum against UVA radiation. This will enable individuals with

TABLE XVII - Occlusion factors (F) of the NPB1 base, NPB2 base and corrective makeup after $6 \mathrm{~h}, 24 \mathrm{~h}$ and $48 \mathrm{~h}$

\begin{tabular}{cccccccc}
\hline \multicolumn{7}{c}{ OCCLUSION FACTOR (F) } \\
\hline TIME & NPB1 & NPB2 & BEIGE I & BEIGE II & BEIGE III & BRONZE & TAN \\
\hline $6 \mathrm{~h}$ & $45.18 \pm 3.01$ & $56.72 \pm 2.63$ & $63.59 \pm 1.72$ & $63.89 \pm 1.73$ & $62.56 \pm 1.84$ & $62.75 \pm 0.49$ & $63.04 \pm 0.54$ \\
$24 \mathrm{~h}$ & $29.21 \pm 2.26$ & $54.83 \pm 2.34$ & $55.17 \pm 0.92$ & $56.41 \pm 2.38$ & $55.68 \pm 1.17$ & $56.73 \pm 1.02$ & $56.42 \pm 0.61$ \\
$48 \mathrm{~h}$ & $30.75 \pm 2.36$ & $54.29 \pm 1.93$ & $55.03 \pm 2.92$ & $55.12 \pm 1.32$ & $54.84 \pm 2.35$ & $55.97 \pm 0.72$ & $55.18 \pm 0.81$ \\
\hline
\end{tabular}


dyschromia to protect themselves from the harmful effects of solar radiation.

It is believed that the formulation tested in this study will bring great benefits to patients with skin pigmentation disorders, improving their self-esteem and reducing their negative attitude towards these skin conditions. It is expected that the corrective makeup developed and tested will make a big difference to the quality of life of patients with dyschromia by helping them to cover their skin spots and enabling them to engage in social activities without feeling different from individuals without these conditions. Finally, this will foster a reduction in psychological, emotional, and social injury caused by these diseases.

\section{ACKNOWLEDGEMENTS}

The authors would like to thank Dr ${ }^{\mathrm{a}}$. Elisabete Pereira dos Santos for allowing this work had being fully carried out in the Galenic Development Laboratory of the Pharmacy Faculty of UFRJ.

\section{REFERENCES}

Antoniou C, Stefanaki C. Cosmetic camouflage. J Cosmet Dermatol. 2006;5(4):297-301.

Agência Nacional de Vigilância Sanitária (Brasil). Guia de Estabilidade de Produtos Cosméticos. 1 ed. Brasília: ANVISA; 2004. v. 1,52 p.

Agência Nacional de Vigilância Sanitária (Brasil). Resolução RDC n ${ }^{\circ} 30$ de $1^{\circ}$ de junho de 2012. Regulamento Técnico Mercosul sobre Protetores Solares em Cosméticos. Diário Oficial da República Federativa do Brasil, Brasília; 2012.

Ayanlowo O, Olumide YM, Akinkugbe A, Ahamneze N, OtikeOdibi BL, Ekpudu VL, et al. Characteristics of vitiligo in Lagos, Nigeria. West Afr J Med. 2009;28(2):118-21.

Brandão L. Índex ABC - Ingredientes para a Indústria de Produtos de Higiene Pessoal, Cosméticos e Perfumes. 1(A-J). São Paulo: Pharmabooks; 2009a.

Brandão L. Índex ABC - Ingredientes para a Indústria de Produtos de Higiene Pessoal, Cosméticos e Perfumes. 2(K-Z). São Paulo: Pharmabooks; 2009b.

Cerqueira-Coutinho C, Santos-Oliveira R, Santos E, Mansur, CR. Development of a photoprotective and antioxidant nanoemulsion containing chitosan as an agent for improving skin retention. Eng Life Sci. 2015;15(6):593-604.
Clares B, Gálvez P, Gallardo V, Ruiz MA. Elaboration, characterization, and stability study of a sunscreen emulsion for use as a towelette application in pediatric photoprotection. J Cosmet Sci. 2011;62(4):371-382.

Colipa - The European Cosmetic, Toiletry and Perfumary Association. In Vitro Method for the Determination of the UVA Protection Factor and "Critical Wavelength" Values of Sunscreen Products, Brussels; 2009.

Deuschle VCKN, Deuschle RAN, Bortoluzzi MR, Athayde ML. Physical chemistry evaluation of stability, spreadability, in vitro antioxidant, and photo-protective capacities of topical formulations containing Calendula officinalis L. leaf extract. Braz J Pharm Sci. 2015;51(1):63-75.

Dwivedi M, Kemp EH, Laddha NC, Mansuri MS, Weetman AP, Begum R. Regulatory T cells in vitiligo: Implications for pathogenesis and therapeutics. Autoimmun Rev. 2015;14(1):49-56.

Fernándes-Montes EA. Técnicas y procedimientos en formulación magistral dermatológica. Madrid: E. Alía; 2005. $341 \mathrm{p}$.

Fitzpatrick TB. The validity and practicality of sun-reactive skin types I through VI. Arch Dermatol. 1988;124(6):869-871.

Freitas ZMF, Gonçalves JCS, Santos EP, Vergnanini A. Glyceridic esters of p-methoxycinnamic acid. A new sunscreen of the cinnamate class. Int J Cosmet Sci. 2001;23(3):147-152.

Garoli D, Pelizzo MG, Bernardini B, Nicolosi P, Alaibac M. Sunscreen tests: correspondence between in vitro data and values reported by the manufacturers. J Dermatol Sci. 2008;52(3):193-204.

Hojerová J, Medovcíková A, Mikula M. Photoprotective efficacy and photostability of fifteen sunscreen products having the same label SPF subjected to natural sunlight. Int J Pharm. 2011;408(1-2):27-38.

Hossain C, Porto DA, Hamzavi I, Lim HW. Camouflaging agents for vitiligo patients. J Drugs Dermatol. 2016;15(4):384387.

Kaliyadan F, Kumar A. Camouflage for patients with vitiligo. Indian J Dermatol Venereol Leprol. 2012;78(1):8-15.

Kockler J, Oelgemöller M, Robertson S, Glass BD. Photostability of sunscreens. J Photochem Photobiol C Photochem Rev. 2012;13(1):91-110. 
Krüger C, Schallreuter KU. A review of the worldwide prevalence of vitiligo in children/adolescents and adults. Int $\mathrm{J}$ Dermatol. 2012;51(10):1206-1212.

Labsphere. User manual UV-2000 S Ultraviolet Transmittance Analyzer. AQ-02755-000, Rev. 3., Labsphere, Inc., North Sutton; 2008.

Lai-Cheong JE, MacGrath JA. Structure and function of skin, hair and nails. Medicine. 2013;41(6):317-320.

Levy LL, Emer JJ. Emotional benefit of cosmetic camouflage in the treatment of facial skin conditions: personal experience and review. Clin Cosmet Investig Dermatol. 2012;5(1):173-82.

Longo C, Casari A, Beretti F, Cesinaro AM, Pellacani G. Skin aging: In vivo microscopic assessment of epidermal and dermal changes by means of confocal microscopy. J Am Acad Dermatol. 2013;68(3):73-82.

Mansur JS, Breder MNR, Mansur MCA, Azulay RD. Determinação do fator de proteção solar por espectrofotometria. An Bras Dermatol. 1986;61(3):121-124.

Mansur MCPPR, Leitão SG, Cerqueira-Coutinho C, Vermelho $\mathrm{AB}$, Silva RS, Presgrave OAF, et al. In vitro and in vivo evaluation of efficacy and safety of photoprotective formulations containing antioxidant extracts. Braz J Pharmacog. 2016;26(1):251-258.

Mollet H, Grubenmann A. Solid forms. In: Formulation technology: emulsions, suspensions, solid forms. New York: John Wiley \& Sons; 2008. p. 181-189.

Miksa S, Lutz D, Guy C. Sandblasting to improve the reproducibility of in vitro sunscreen evaluation. Cosmet Toil. 2014;129(3):30.

Miksa S, Lutz D, Guy C. New approach for a reliable in vitro sun protection factor method. Part I: Principle and mathematical aspects. Int J Cosmet Sci. 2015;37(6):1-12.

Nesseem D. Formulation of sunscreens with enhancement sun protection factor response based on solid lipid nanoparticles. Int J Cosmet Sci. 2011;33(1):70-79.
Polefka TG, Meyer TA, Agin PP, Bianchini RJ. Effects of solar radiation on the skin. J Cosmet Dermatol. 2012;11(2):134-143.

Santos EP, Freitas ZM, Souza KR, Garcia S, Vergnanini A. In vitro and in vivo determinations of sun protection factors of sunscreen lotions with octylmethoxycinnamate. Int J Cosmet Sci. 1999;21(1):1-5.

Sarveswari K. Cosmetic camouflage in vitiligo. Indian J Dermatol. 2010;55(3):211-214.

Seité S, Deshayes P, Dréno B, Misery L, Reygagne P, Saiag P, et al. Interest of corrective makeup in the manegement of patients in dermatology. Clin Cosmet Investig Dermatol. 2012;5:123128.

Smaoui S, Hlima HB, Chobba IB, Kadri A. Development and stability studies of sunscreen cream formulations containing three photo-protective filters. Arab J Chem. 2013;1:1-7.

Stiefel C, Schwack W. Photoprotection in changing times - UV filter efficacy and safety, sensitization processes and regulatory aspects. Int J Cosmet Sci. 2015;37(1):2-30.

Tanioka M, Yamamoto Y, Kato M, Miyachi Y. Camouflage for patients with vitiligo vulgaris improved their quality of life. J Cosmet Dermatol. 2010;9(1):72-75.

Teeranachaideekul V, Boonme P, Souto EB, Müller RH, Junyaprasert VB. Influence of oil content on physicochemical properties and skin distribution of Nile red-loaded NLC. J Control Release. 2008;128(2):134-141.

Thompson AR, Clarke AR, Newell RJ, Gawkrodger DJ. Vitiligo linked to stigmatization in British South Asian women: A qualitative study of the experiences of living with vitiligo. $\mathrm{Br} \mathrm{J}$ Dermatol. 2010;163(3):481-486.

Wissing SA, Müller RH. The influence of the crystallinity of lipid nanoparticles on their occlusive properties. Int J Pharm. 2002;242(1-2):377-379.

Received for publication on $14^{\text {th }}$ June 2017 Accepted for publication on $28^{\text {th }}$ March 2018 